\title{
Chá verde brasileiro (Camellia sinensis var assamica): efeitos do tempo de infusão, acondicionamento da erva e forma de preparo sobre a eficiência de extração dos bioativos e sobre a estabilidade da bebida
}

\author{
Brazilian green tea (Camellia sinensis var assamica): effect of infusion time, mode of packaging and \\ preparation on the extraction efficiency of bioactive compounds and on the stability of the beverage
}

\author{
Márcia Fernandes NISHIYAMA ${ }^{1}$, Maria Aparecida Ferreira COSTA ${ }^{1}$, Andréa Miura da COSTA ${ }^{1}$, \\ Cristina Giatti Marques de SOUZA ${ }^{1}$, Cinthia Gandolfi BÔER ${ }^{1}$, Cissa Kelmer BRACHT ${ }^{1}$, Rosane Marina PERALTA ${ }^{1 *}$
}

\begin{abstract}
Resumo
Os estudos do chá verde brasileiro (Camellia sinensis var assamica) ainda são escassos quando comparados aos realizados com chás verdes produzidos em outros países. Os objetivos deste trabalho foram avaliar os efeitos do tempo de infusão, forma de acondicionamento da erva (a granel ou em sachês) e forma de preparo da bebida na extração dos biativos do chá verde brasileiro e na estabilidade da bebida obtida. Foram avaliados os parâmetros sólidos solúveis e compostos fenólicos extraídos, bem como as propriedades antioxidantes da bebida pelo método DPPH (radicais 2,2-difenil-1-picrilhidrazil). Os dados obtidos evidenciam que o uso da erva a granel sob agitação e tempo de infusão de 5 minutos foi a condição mais propícia para a extração dos bioativos do chá verde. Aumentando-se o volume de preparação da bebida sem alteração da razão erva:água, aumentou-se a eficiência da extração dos bioativos, devido ao fato de que o resfriamento de volumes maiores é mais demorado que o resfriamento de volumes menores. As bebidas obtidas foram estáveis por 24 horas em temperatura ambiente e em geladeira, visto não terem sido detectadas redução das propriedades antioxidantes e variações significativas dos seus principais bioativos epigalocatequina galato, epicatequina, catequina e cafeína.
\end{abstract}

Palavras-chaves: atividade antioxidante; chá verde brasileiro; compostos fenólicos; estabilidade.

\begin{abstract}
Studies on the Brazilian green tea (Camellia sinensis var assamica) are still scarce when compared with the great number of investigations conducted on the green tea produced in other countries. The purposes of the present study were to evaluate the effects of infusion time, mode of packaging (tea in bulk or in tea bags) and preparation on the extraction of bioactive compounds from the Brazilian green tea and on the stability of the beverage. The evaluated parameters were: the amounts of soluble solutes and phenolic compounds that were extracted as well as the antioxidant properties of the beverage using the DPPH method (2,2-diphenyl-1-picrylhydrazyl radicals). The results revealed that the use of the herb in bulk with 5 minutes stirring was the most adequate condition for the extraction of bioactive compounds from the green tea. Increases in the volume of the preparation without changes in the herb/water ratio increased the efficiency of the bioactive compounds extraction due to the fact that cooling a large volume of water is delayed in comparison to cooling smaller volumes. It can be said that the obtained beverages were stable for 24 hour at room temperature and in the refrigerator since no decrease in the antioxidant properties and significant changes in the contents of the major bioactive coumpounds, namely epigallocatechin gallate, epicatechin, catechin, and caffeine were detected.
\end{abstract}

Keywords: antioxidant activity; Brazilian tea; green tea; phenolic compounds; stability.

\section{Introdução}

Originário da China, o chá é cultivado e consumido pelas suas características de aroma e sabor e propriedades medicinais em mais de 160 países, especialmente asiáticos (KUMUDAVALLY et al., 2008; SAITO; MIYATA, 2000). Os chás de Camellia sinensis podem ser classificados em três tipos básicos: preto, verde e oolong, diferenciando-se pelo beneficiamento das folhas. Para o preparo do chá preto, as folhas são fermentadas. Para o preparo do chá verde, as folhas são apenas escaldadas e fervidas para garantir a preservação da cor. Os chás oolong encaixam-se numa categoria intermediária: passam por um processo de fermentação mais brando e, por isso, têm aroma menos acentuado do que os pretos. Dos três tipos de chás, o chá verde é o mais rico em compostos com atividades funcionais (CHENG, 2006).

Enquanto nos países orientais o chá mais consumido é o verde, no Ocidente o mais consumido é o chá preto, embora o consumo do chá verde venha crescendo, devido principalmente à divulgação de suas propriedades funcionais. Diversos estudos têm mostrado os benefícios do consumo de chá verde, incluindo redução dos níveis de colesterol, atividades imunoestimulatória, antimicrobiana e antioxidante, auxiliando na prevenção de doenças crônico-degenerativas, como o câncer e doenças cardiovasculares (CHENG, 2006; IKEDA et al., 2003;

${ }^{1}$ Departamento de Bioquímica, Universidade Estadual de Maringá - UEM, CEP 87020-900, Maringá - PR, Brasil, E-mail: rmperalta@uem.br

${ }^{*}$ A quem a correspondência deve ser enviada 
SAITO; MIYATA, 2000; SOARES, 2002; WANG; PROVAN; HELLIWELL, 2000).

As propriedades funcionais do chá são devidas ao seu conteúdo em polifenólicos. Uma bebida típica preparada como infusão em água quente por 3 minutos de $1 \mathrm{~g}$ de erva para $100 \mathrm{ml}$ de água, contém geralmente entre 250-350 mg de sólidos solúveis do chá, sendo $30-42 \%$ do peso em catequinas e 3-6\% em cafeína. As principais catequinas do chá são (-) epigalocatequina galato (EGCG), (-) epigalocatequina (EGC), (-) epicatequina galato (ECG), epicatequina (EC) e catequina (C). A catequina mais abundante e ativa do chá verde é a EGCG (NAGLE; FERREIRA; ZHOU, 2006; WANG; PROVAN; HELLIWELL, 2000). Além das catequinas, quantidades apreciáveis de flavonoides como quercetina e miricetina e seus glicosídeos estão presentes no chá verde (SAITO; MIYATA, 2000, WANG et al., 2000).

Os maiores produtores de Camellia sinensis são a China e a Índia e os chás provenientes desses países já foram objeto de muitos estudos (ASTILL et al., 2001; FERNANDEZ et al., 2002; LIN et al., 2003; PERVA-UZUNALIC et al., 2006). O cultivo do chá verde é hoje, entretanto, realizado em diversos países em praticamente todos os continentes (CHAN; LIM; CHEW, 2007; YAO et al., 2005). No Brasil, seu cultivo é restrito ao Vale do Ribeira no Estado de São Paulo, e a maior parte é destinada para a produção do chá preto. $\mathrm{O}$ aumento do interesse do público brasileiro pelo chá verde fez com que a sua produção fosse ampliada, utilizando principalmente o cultivar C. sinensis var assamica IAC 259.

No Brasil, o chá verde é comercializado principalmente acondicionado em saquinhos de papel de filtro (sachê). Estudos têm demonstrado que o chá brasileiro apresenta maior quantidade de compostos fenólicos quando comparado com chás de outros países e tal fato é atribuído às características do clima e do solo (SAITO et al., 2007a, b). Embora algumas características do chá verde produzido no Brasil já tenham sido avaliadas, especialmente quanto aos teores das catequinas presentes (MATSUBARA; RODRIGUES-AMAYA, 2006, SAITO et al., 2007a, b), os estudos do chá verde brasileiro (var. assamica) ainda são escassos quando comparados aos realizados com chás verdes produzidos em outros países. Para que os benefícios do consumo da bebida sejam máximos, são necessários estudos que assegurem as melhores formas de preparo da bebida, garantindo maior extração e estabilidade de seus compostos bioativos. Por isso, este trabalho teve como objetivos: 1) avaliar o efeito do tempo, da forma de acondicionamento da erva (em sachês ou a granel), da forma de preparo enfocando a ação de agitar ou não as misturas e o volume de preparação sobre a extração dos compostos solúveis totais, compostos fenólicos e atividade antioxidante do chá verde brasileiro; 2) avaliar a estabilidade das preparações após armazenamento da bebida pronta em temperatura ambiente $\mathrm{e}$ em geladeira.

\section{Material e métodos}

\subsection{Amostra}

O chá verde utilizado neste estudo foi adquirido no comércio local (Maringá - PR, Brasil). São folhas de Caméllia sinensis var. assamica produzidas no Brasil (Vale do Ribeira), secas, trituradas até textura de pó fino e acondicionadas em sachê.
Metade dos sachês adquiridos foi aberta e os seus conteúdos foram designados como chá a granel.

\subsection{Reagentes}

DPPH (radicais 2,2-difenil-1-picrilhidrazil), reagente de Folin-Ciocalteu, catequinas (EGCG, EC e C) e cafeína foram adquiridos de Sigma $\mathrm{Co}^{\circ}$. Os demais reagentes utilizados foram de grau analítico.

\subsection{Preparo do chá}

As seguintes variáveis foram estudadas: forma de acondicionamento (em sachê ou a granel), tempo de infusão (2,5; 5 ; e 10 minutos), forma de preparo englobando agitação de $50 \mathrm{rpm}$ ou não (estático) e volume de infusão $(50,100$, 200 e $500 \mathrm{~mL}$ ). Consideramos tempo de infusão máximo de 10 minutos, visto que tempos de infusão superiores a 10 minutos não são indicados no preparo do chá verde por diversos autores, devido principalmente à liberação de taninos, que confere sabor adstringente ao chá, e a bebida ganha um sabor amargo que não agrada aos consumidores.

Para o preparo dos chás com agitação, as misturas foram mantidas em um agitador magnético marca Fisatom modelo 752. No estudo das três primeiras variáveis, um volume de $200 \mathrm{~mL}$ de água quente $\left(79 \pm 2{ }^{\circ} \mathrm{C}\right)$ foi adicionado a $1,75 \mathrm{~g}$ da erva em béquer de vidro de $500 \mathrm{~mL}$. Imediatamente os béqueres foram tampados utilizando-se um vidro de relógio e as misturas mantidas em bancada de laboratório (temperatura ambiente de $25 \pm 2{ }^{\circ} \mathrm{C}$ ). Nos tempos indicados, os chás preparados com a erva a granel foram filtrados a vácuo em papel de filtro comum previamente tarado para eliminação dos sólidos residuais. Os chás preparados com a erva acondicionada em sachês foram removidos manualmente. Em ambos os casos, as preparações obtidas foram imediatamente utilizadas ou congeladas a $-20^{\circ} \mathrm{C}$, para análises posteriores.

Para avaliar o efeito do volume do infuso na eficiência de extração dos compostos solúveis do chá verde, foi utilizada a mesma proporção erva:água dos experimentos acima: $0,44 \mathrm{~g}$ para $50 \mathrm{~mL}$ de água, $0,87 \mathrm{~g}$ para $100 \mathrm{~mL}$ de água e $4,35 \mathrm{~g}$ para $500 \mathrm{~mL}$ de água. Neste caso, utilizou-se a erva a granel, forma de preparo estática e tempo de infusão de 5 minutos. Após 5 minutos, as temperaturas das misturas foram aferidas utilizando-se um termômetro, e imediatamente procedeu-se à filtração a vácuo para eliminação dos sólidos residuais. Todas as outras condições foram idênticas às descritas acima.

\subsection{Determinação dos sólidos solúveis}

Para determinação dos sólidos solúveis extraídos, os sólidos residuais das ervas a granel foram secos em estufa de circulação forçada a $45^{\circ} \mathrm{C}$ até peso constante. Os pesos dos sólidos solúveis extraídos foram obtidos subtraindo-se os pesos dos sólidos residuais dos pesos iniciais da erva. Quando se utilizou a erva acondicionada, os sachês também foram igualmente secos até peso constante e os sólidos residuais foram cuidadosamente removidos e pesados em balança analítica. 


\subsection{Determinação dos compostos fenólicos totais}

A concentração de compostos fenólicos totais nas amostras foi determinada pelo método de Folin-Ciocalteu (SINGLETON; ROSSI, 1965), utilizando catequina como padrão.

\subsection{Determinação da atividade antioxidante}

A atividade antioxidante foi determinada pelo ensaio do DPPH (radicais 2,2-difenil-1-picrilhidrazil), que avalia a eficiência do sequestro dos radicais livres, sendo um método largamente utilizado para determinação de atividade antioxidante de vinhos, sucos de frutas e chás (CHAN; LIM; CHEW, 2007; NANJO et al., 1996; ZAPOROZHETS et al., 2004). O DPPH (0,024 g) foi dissolvido em $100 \mathrm{~mL}$ de metanol. Um volume de $10 \mathrm{~mL}$ desta solução foi adicionado a $45 \mathrm{~mL}$ de metanol, medindo-se a sua absorbância a $515 \mathrm{~nm}$. Quando necessário, adicionou-se metanol até a obtenção de uma absorbância de 1,1. A 2,85 mL da solução metanólica de DPPH adicionou-se $0,15 \mathrm{~mL}$ da amostra. Após 4 horas no escuro em temperatura ambiente, a absorbância foi determinada a $515 \mathrm{~nm}$. A atividade antioxidante foi expressa como percentagem de eficiência do sequestro dos radicais livres. Atividade antioxidante $(\%)=\left(1-\mathrm{A}_{\text {amostra }} / \mathrm{A}_{\text {controle }}\right) \times 100$. BHT (butil hidroxitolueno, $\left.0,2 \mathrm{mg} \cdot \mathrm{mL}^{-1}\right)$ serviu como controle positivo de atividade antioxidante e a água como controle negativo.

\subsection{Determinação da estabilidade das preparações}

Para estudar a estabilidade das preparações, todos os chás obtidos com tempo de infusão de 5 minutos foram divididos em 3 porções de mesmo volume, sendo que uma delas foi imediatamente testada quanto ao conteúdo em compostos fenólicos e atividade antioxidante, conforme descrito nos itens 2.5 e 2.6, respectivamente as duas outras porções foram mantidas em frascos de vidro abertos em temperatura ambiente $\left(25 \pm 2{ }^{\circ} \mathrm{C}\right)$ e em geladeira $\left(8 \pm 1^{\circ} \mathrm{C}\right)$ por 24 horas. Após o período de estocagem, os conteúdos em compostos fenólicos totais e as atividades antioxidantes das amostras também foram determinados. Volumes de $50 \mathrm{~mL}$ dos extratos frescos e dos extratos mantidos por 24 horas em temperatura ambiente e em geladeira foram liofilizados e mantidos a $-20^{\circ} \mathrm{C}$ para posteriores análises cromatográficas. Para as análises cromatográficas, os materiais liofolizados foram ressuspensos em $1 \mathrm{~mL}$ de água. Primeiramente, os compostos fenólicos e as atividades antioxidantes dos materiais concentrados foram avaliados por cromatografia em camada delgada. Para tanto, um volume de $10 \mu \mathrm{l}$ de cada amostra foi aplicado em placas de sílica gel (Polygram Sil G, Macherey-Nagel, Alemanha) e resolvidos, utilizando-se como fase móvel água:acetonitrila:metanol:ac etato de etila:ácido acético glacial (89:6:1:3:1) (SAITO et al., 2006). Todas as análises cromatográficas foram realizadas a $25 \pm 2{ }^{\circ} \mathrm{C}$. Após secas, as placas foram reveladas por duas soluções reveladoras. A revelação para compostos fenólicos foi feita utilizando-se uma solução de cloreto férrico-ferricianeto de potássio $\left[\mathrm{FeCl}_{3}-\mathrm{K}_{2} \mathrm{Fe}(\mathrm{CN})_{6}\right]$. Os compostos fenólicos presentes são revelados em azul (BARTON; EVANS; GARDNER, 1952). A revelação para atividade antioxidante foi realizada borrifando-se a placa com solução metanólica de $0,04 \%$ DPPH. Os compostos com atividade antioxidante aparecem como manchas amareladas contra fundo púrpura. Posteriormente, os extratos concentrados foram submetidos à cromatografia líquida de alta eficiência (CLAE), utilizando-se metodologia descrita em SAITO et al. (2006). As análises foram realizadas em aparelho da marca Shimadzu, modelo SPD-20A. A coluna utilizada foi Superspher 100-4 R C-18 (Macherey- Nagel, $125 \times 2 \mathrm{~mm}, 4 \mu \mathrm{m}$ ) e a fase móvel utilizada foi água:acetonitrila:metanol:acetato de etila:ácido acético glacial (89:6:1:3:1) (SAITO et al., 2006; SAITO et al., 2007a) com um fluxo de $0,7 \mathrm{~mL} /$ minuto por 20 minutos. A detecção foi realizada a $280 \mathrm{~nm}$. Todas as CLAEs foram realizadas a $20 \pm 2{ }^{\circ} \mathrm{C}$. Para identificar os principais bioativos do chá verde, padrões de cafeína, catequina, epicatequina e epigalocatequina galato foram aplicados isoladamente, seguindo a mesma metodologia (SAITO et al., 2006).

\subsection{Análises estatísticas}

Todas as determinações foram efetuadas em triplicatas e os dados obtidos foram submetidos ao cálculo de média, desvio padrão e análise de variância, utilizando o programa Graph $\mathrm{Pad}^{\circledast}$, Prisma, 3.0 e o teste de Tukey para a comparação de médias com significância a 5\%.

\section{Resultados e discussão}

\subsection{Extração de sólidos totais, atividade antioxidante e compostos fenólicos: efeito do tempo de infusão, acondicionamento da erva e forma de preparo da bebida}

Os efeitos do tempo de infusão, acondicionamento da erva e forma de preparo na extração dos sólidos totais e compostos fenólicos e atividade antioxidante da bebida estão apresentados na Figura 1. Para os três parâmetros avaliados, os melhores resultados foram obtidos utilizando-se a erva a granel sob agitação, seguida da erva a granel em condições estacionárias. $\mathrm{O}$ acondicionamento do chá em sachês foi, portanto, desfavorável para a extração dos sólidos solúveis (Figura 1a), da atividade antioxidante (Figura 1b) e dos compostos fenólicos (Figura 1c). A agitação das misturas favoreceu a extração tanto para o chá a granel quanto para o chá acondicionado em sachês. Resultados semelhantes foram obtidos em estudo utilizando chá verde de procedência chinesa (ASTILL et al., 2001). Na Figura 1, é possível observar também que, para os três parâmetros avaliados, a utilização de tempo de extração de 10 minutos não apresentou valores significativamente diferentes do tempo de extração de 5 minutos $(\mathrm{p}>0,05)$ para todas as formas de extração utilizadas.

Estudos prévios sobre o preparo do chá verde têm demonstrado que o modo de preparo, tempo de infusão, forma de acondicionamento da erva, temperatura e a proporção peso seco da erva/quantidade de água utilizada têm grande influência na quantidade de compostos fenólicos e nas atividades antioxidantes extraídas (ASTILL et al., 2001; CHEN et al., 2001; ZHU et al., 1997). No presente estudo, foi avaliado também o efeito do volume de extração, mantendo-se sempre a mesma proporção de erva:água. A temperatura inicial foi padronizada em $79 \pm 1{ }^{\circ} \mathrm{C}$. Quanto maior a quantidade de água utilizada para a mesma proporção de erva:água, maior a eficiência da extração de compostos fenólicos do chá (Figura 2). A razão de uma maior eficiência de extração ser obtida aumentando-se o volume de preparação sem alterar a razão erva:água reside no 

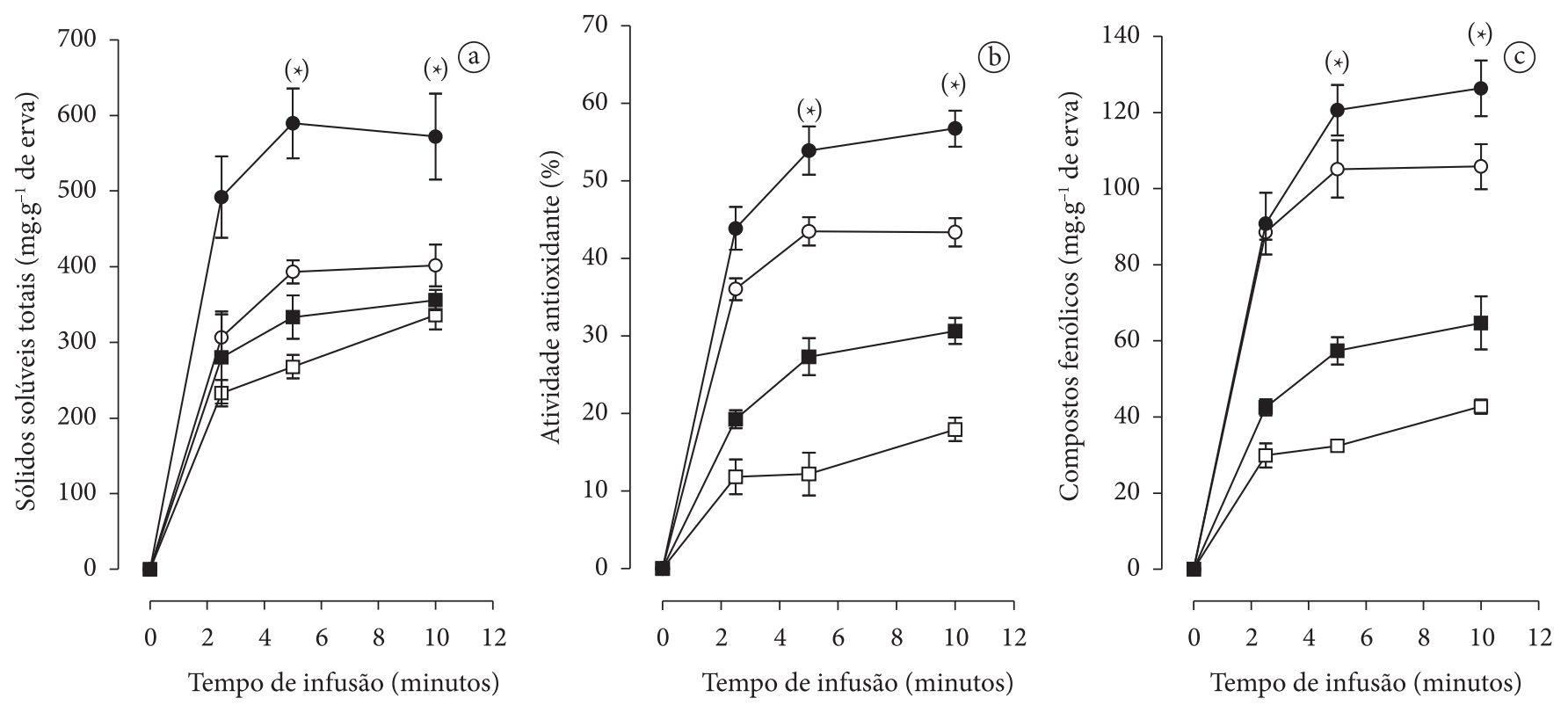

- Erva a granel preparada com infusão sob agitação

- Erva a granel preparada com infusão sem agitação

- Erva acondicionada em sachê preparada com infusão sob agitação

$\square$ Erva acondicionada em sachê preparada com infusão sem agitação

Figura 1. Efeito do tempo de infusão, acondicionamento de amostra e forma de preparo na extração dos bioativos do chá verde. a) sólidos solúveis; b) atividade antioxidante; c) compostos fenólicos. Os pontos marcados com $(*)$ diferem significativamente dos demais e não diferem entre si.

fato de que, quanto maior o volume de água utilizado, mais lentamente ocorre a redução da temperatura durante o tempo de infusão, neste caso de 5 minutos. Com $50 \mathrm{~mL}$ de água, ocorreu um resfriamento rápido e, após os 5 minutos de infusão, a temperatura da mistura havia caído de 79 para $50^{\circ} \mathrm{C}$. Quando se prepararam $500 \mathrm{~mL}$ de chá, a temperatura da mistura, após 5 minutos de infusão, caiu para $62^{\circ} \mathrm{C}$. Tal resultado corrobora as conclusões de Astill et al. (2001), que consideraram a temperatura como o fator que mais contribui para a eficiência da extração dos bioativos do chá.

\subsection{Análise da estabilidade dos compostos fenólicos e da atividade antioxidante do chá verde}

Vários estudos sobre a estabilidade das preparações à base de chá verde têm sido realizados, principalmente com o chá de procedência chinesa. Entre os fatores que podem interferir com a estabilidade, a temperatura parece ser o mais importante, considerando que temperaturas elevadas causam epimerização das catequinas (WANG; HELLIWELL, 2000). Para avaliar a estabilidade das infusões do chá verde brasileiro, a atividade antioxidante e a concentração de fenólicos totais das infusões foram avaliadas imediatamente após o preparo e após 24 horas de armazenamento em temperatura ambiente e em geladeira. Este estudo de estabilidade foi realizado com todas as formas de preparação do chá utilizadas neste trabalho. Nas Figuras 3 a 5 , são apresentados os resultados obtidos com o chá preparado utilizando-se a erva a granel, forma de preparo estática, tempo de infusão de 5 minutos e volume de infusão de $200 \mathrm{ml}$, por ser representativo de todos os outros resultados obtidos. Em ambas

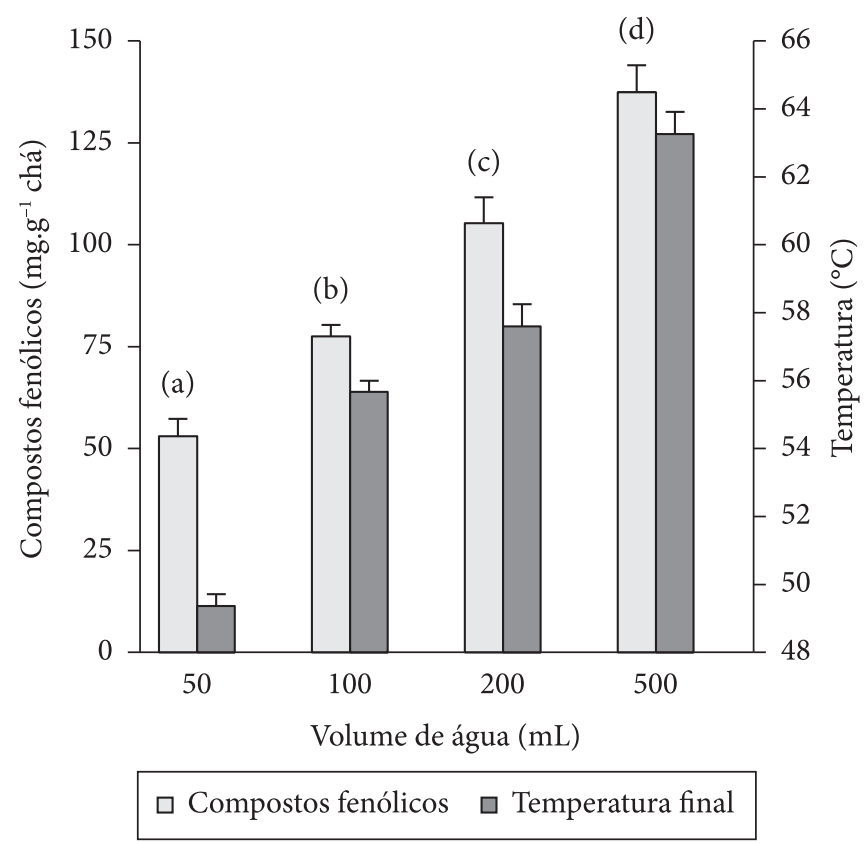

Figura 2. Efeito do volume de água na extração de compostos fenólicos do chá verde. As extrações foram realizadas utilizando-se sempre a mesma proporção água:chá verde: $50 \mathrm{~mL}$ de água/0,437 g de erva; $100 \mathrm{~mL}$ de água/0,875 g de erva; $200 \mathrm{~mL}$ de água/1,75 g de erva; e $500 \mathrm{~L}$ de água/4,375 g de erva. Para maiores detalhes, ver item 2.3. da seção Material e métodos. Médias identificadas com letras diferentes diferem estatisticamente $(\mathrm{p}<0,05)$. 


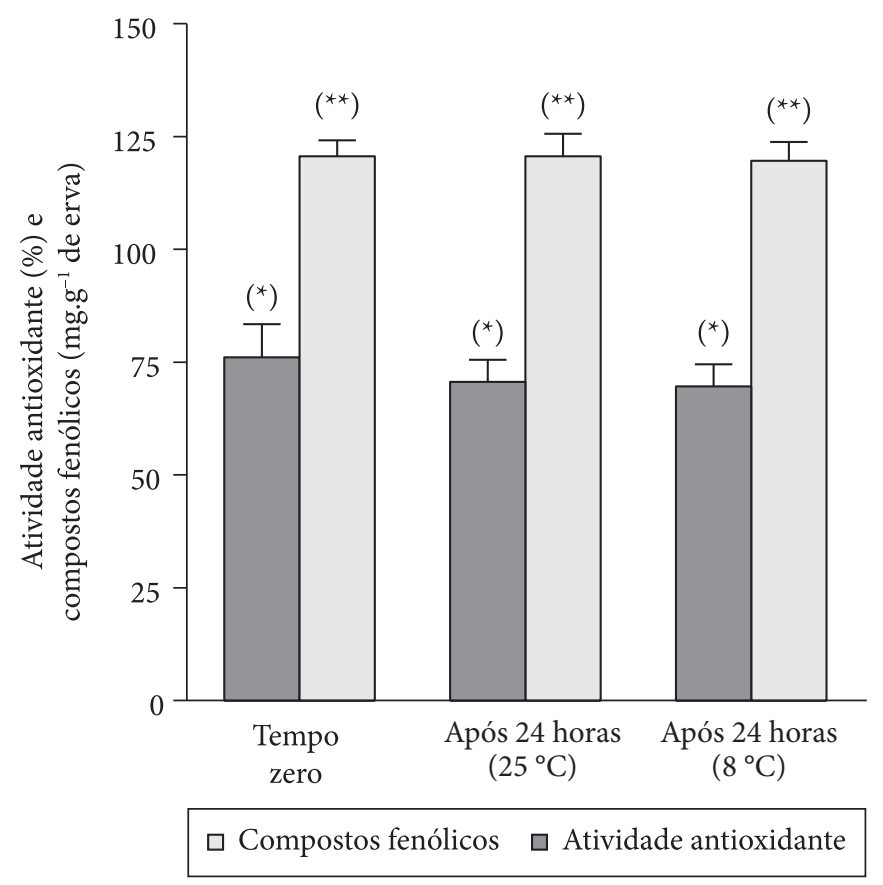

Figura 3. Avaliação da estabilidade da atividade antioxidante e do teor em compostos fenólicos do chá verde brasileiro. As atividades antioxidantes e os conteúdos em compostos fenólicos das bebidas foram determinados imediatamente após o preparo (tempo zero) e após 24 horas de armazenamento em temperatura ambiente ou em geladeira. Para maiores detalhes ver item 2.7 da seção Material e métodos. Médias identificadas com o mesmo símbolo não diferem significativamente.

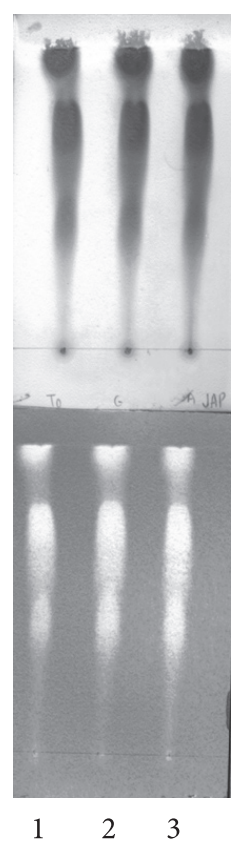

Figura 4. Avaliação da estabilidade das preparações de chá verde por cromatografia em camada delgada. As preparações foram liofilizadas imediatamente após a infusão (1) ou mantidas por 24 horas em temperatura ambiente (2) e em geladeira (3) e posteriormente liofilizadas. Na placa superior, os compostos fenólicos (que coram em azul) foram revelados utilizando solução de cloreto férrico-ferricianeto de potássio. A placa inferior foi revelada com solução metanólica de DPPH $0,04 \%$, que revela a atividade antioxidante como manchas amareladas contra fundo púrpura.
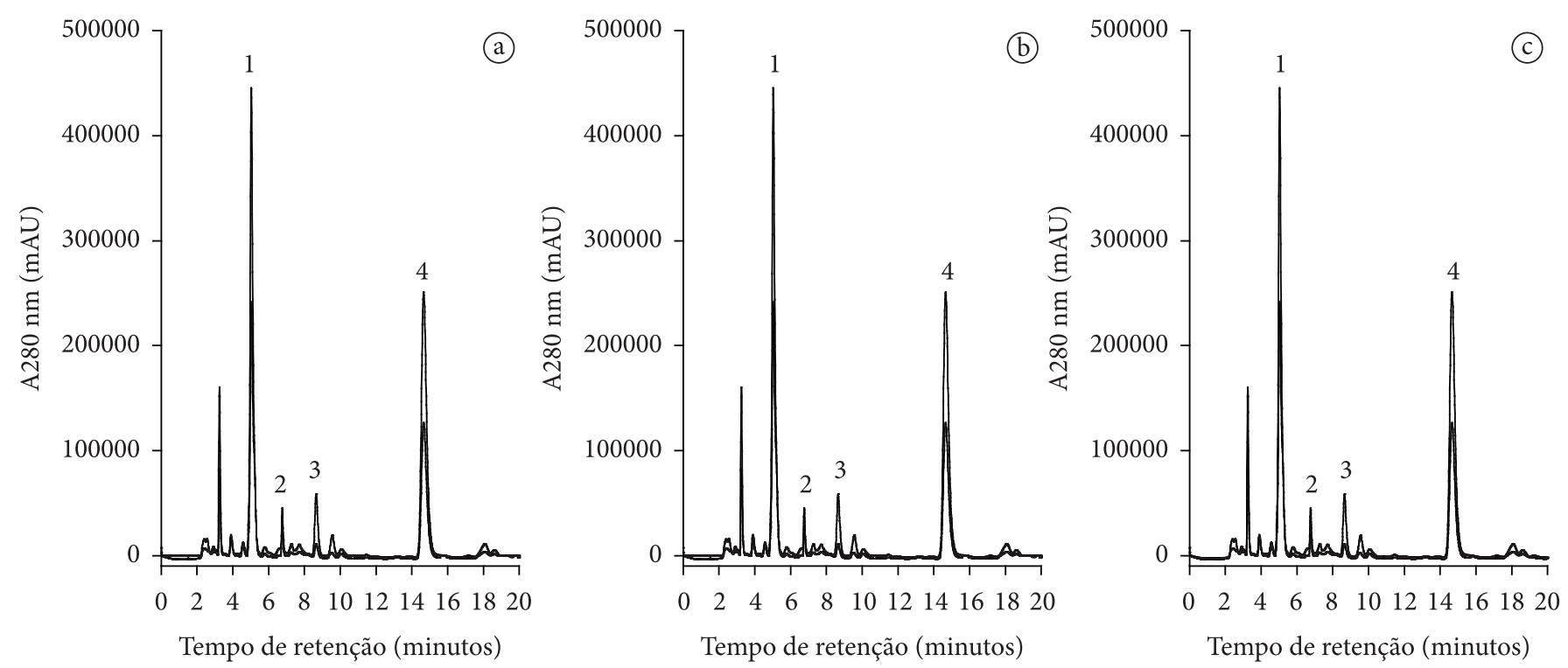

Figura 5. Avaliação da estabilidade das preparações de chá verde por CLAE. A bebida pronta foi liofilizada imediatamente após seu preparo a) ou mantida por 24 horas em temperatura ambiente b) ou em geladeira c) e em seguida liofilizadas. Utilizou-se uma coluna Superspher 100-4 R P-18 (Macherey-Nagel, $125 \times 2 \mathrm{~mm}, 4 \mu \mathrm{m}$ ) como fase móvel água:acetonitrila:metanol:acetato de etila:ácido acético glacial (89:6:1:3:1) com um fluxo de $0,7 \mathrm{ml} /$ minuto por 20 minutos. A detecção foi realizada a $280 \mathrm{~nm}$. Todas as análises cromatográficas foram realizadas a $20 \pm 2{ }^{\circ} \mathrm{C}$. A comparação dos tempos de retenção de padrões seguindo a mesma metodologia permitiu identificar os principais bioativos como sendo cafeína (1), catequina (2), epicatequina (3) e epigalocatequina galato (4). 
as condições de armazenamento, em temperatura ambiente e em geladeira, as atividades antioxidantes e os conteúdos em fenólicos totais das preparações após 24 horas de armazenamento não variaram significativamente $(\mathrm{p}>0,05)$ daquelas obtidas imediatamente após o preparo da bebida (Figura 3).

Para verificar se o armazenamento das infusões por 24 horas poderia ter causado alterações químicas nos compostos fenólicos da bebida, amostras das infusões foram liofilizadas imediatamente após seu preparo e após 24 horas em temperatura ambiente ou em geladeira. Os extratos concentrados foram analisados por cromatografia em camada delgada e por CLAE. Nenhuma alteração foi observada na atividade antioxidante e nos compostos fenólicos na análise por cromatografia em camada delgada (Figura 4). Na Figura 5, é possível observar que os mesmos picos foram obtidos nos extratos concentrados imediatamente após o preparo do chá (Figura 5a) e após 24 horas em temperatura ambiente (Figura 5b) e em geladeira (Figura 5c). A aplicação de padrões, seguindo a mesma metodologia, permitiu identificar os principais bioativos do chá verde: cafeína (1), catequina (2), epicatequina (3) e epigalocatequina galato (4). Considerando-se que os perfis cromatográficos obtidos foram semelhantes e a não existência de outros picos, é possível sugerir que não ocorreram alterações significativas nas estruturas dos principais bioativos do chá verde.

\section{Conclusões}

Os dados obtidos neste trabalho indicam que: 1) para um total aproveitamento de suas propriedades antioxidantes, o chá verde brasileiro deve ser preparado com tempo de infusão de pelo menos 5 minutos, sob agitação leve e a granel, pois o acondicionamento do chá em sachês reduziu a extração dos compostos bioativos do chá; 2) para uma mesma razão erva:água, houve uma eficiência maior na extração dos bioativos do chá quando volumes maiores da bebida foram preparados; 3) a bebida preparada mostrou-se estável ao armazenamento em temperatura ambiente e em geladeira por 24 horas, sem aparentes alterações em seus principais bioativos e sem perdas das suas propriedades antioxidantes. Desta forma, o consumidor pode preparar o chá, mantê-lo em geladeira ou mesmo em temperatura ambiente e consumi-lo ao longo do dia.

\section{Referências bibliográficas}

ASTILL, C. et al. Factors affecting the caffeine and polyphenol contents of black and green tea infusions. Journal of Agricultural and Food Chemistry, v. 49, n. 11, p. 5340-5347, 2001.

BARTON, G. M.; EVANS, R. S.; GARDNER, J. A. F. Paper chromatography of phenolics substances. Nature, v. 170, p. 249-250, 1952.

CHAN, E. W. C.; LIM, Y. Y.; CHEW, Y. L. Antioxidant activity of Camellia sinensis leaves and tea from a lowland plantation in Malaysia. Food Chemistry, v. 102, n. 4, p. 1214-1222, 2007.

CHEN, Z. et al. Degradation of green tea catechins in tea drinks. Journal of Agricultural and Food Chemistry, v. 49, n. 1, p. 477-482, 2001.

CHENG, T. O. All teas are not created equal: the chinese green tea and cardiovascular health. International Journal of Cardiology, v. 108, n. 3, p. 301-308, 2006.
FERNANDEZ, P. L. et al. Study of catechin and xanthine tea profile as geographical tracers. Journal of Agricultural and Food Chemistry, v. 50, n. 7, p. 1833-1839, 2002.

IKEDA, I. et al. Heat-epimerized tea catechins rich in gallocatechin gallate and catechin gallate are more effective to inhibit cholesterol absorption than tea catechins rich in epigallocatechin gallate and epicatechin gallate. Journal of Agricultural and Food Chemistry, v. 51, n. 24, p. 7303-7307, 2003.

KUMUDAVALLY, K. V. et al. Green tea - a potential preservative for extending the shelf life of fresh mutton at ambient temperature $\left(25 \pm 2{ }^{\circ} \mathrm{C}\right)$. Food Chemistry, v. 107, n. 1, p. 426-433, 2008.

LIN, Y. et al. Factors affecting the levels of tea polyphenols and caffeine in tea leaves. Journal of Agricultural and Food Chemistry, v. 51, n. 7, p. 1864-1873, 2003

MATSUBARA, S.; RODRIGUEZ-AMAYA, D. B. Teores de catequinas e teaflavinas em chás comercializados no Brasil. Ciência e Tecnologia de Alimentos, v. 26, n. 2, p. 401-407, 2006.

NAGLE, D. G.; FERREIRA, D.; ZHOU, Y. Epigallocatechin-3-gallate (EGCG): chemical and biomedical perspectives. Phytochemistry, v. 67, n. 17 , p. $1849-1855,2006$.

NANJO, F. et al. Scavenging effects of tea catechins and their derivatives on 1,1 diphenyl 2 picrylhydrazyl radical. Free Radical Biology and Medicine, v. 21, n. 6, p. 895-902, 1996.

PERVA-UZUNALIC, A. et al. Extraction of active ingredients from green tea (Camellia sinensis): extraction efficiency of major catechins and caffeine. Food Chemistry, v. 96, n. 4, p. 597-605, 2006.

SAITO, S. T. et al. Full validation of a simple method for determination of catechins and caffeine in Brazilian green tea (Camelia sinensis var. assamica) using HPLC. Chromatographia, v. 65, n. 9-10, p. 607-610, 2007a.

SAITO, S. T. et al. Characterization of the constituents and antioxidant activity of Brazilian green tea (Camellia sinensis var. assamica IAC-259 cultivar) extracts. Journal of Agricultural and Food Chemistry, v. 55, n. 23, p. 9409-9414, 2007 b.

SAITO, S. T. et al. A method for fast determination of epigallocatechin gallate (EGCC), epicatechin (EC), catechin (C) and caffeine (CAF) in green tea using HPLC. Ciência e tecnologia de Alimentos, v. 26, n. 2, p. 394-400, 2006.

SAITO, T.; MIYATA G. The nutraceutical benefit. Part I: green tea. Nutrition, v. 16, n. 5, p. 315-317, 2000.

SINGLETON, V. L.; ROSSI, J. A. Colorimetry of total phenolics with phosphomolybdic-phosphotungstic acid reagents. American Journal of Enology and Viticulture, v. 16, n. 3, p. 144-158, 1965.

SOARES, S. E. Ácidos fenólicos como antioxidantes. Revista de Nutrição, v. 15, n. 1, p. 71-81, 2002.

WANG, H.; PROVAN, G. J.; HELLIWELL, K. Tea flavonoids: their functions, utilization and analysis. Trends in Food Science and Technolology, v. 11, n. 4-5, p. 152-160, 2000.

WANG, H.; HELLIWELL, K. Epimerisation of catechins in green tea infusions. Food Chemistry, v. 70, n. 3, p. 337-344, 2000.

YAO, L. et al. Seasonal variation of phenolic compounds in Australiagrown tea (Camellia sinensis). Journal of Agricultural and Food Chemistry, v. 53, n. 16, p. 6477-6483, 2005.

ZAPOROZHETS, A. O. et al. A new test method for evaluation of total antioxidant activity of herbal products. Journal of Agricultural and Food Chemistry, v. 52, n. 1, p. 21-25, 2004.

ZHU, Q. Y. et al. Stability of green tea catechins. Journal of Agricultural and Food Chemistry, v. 45, n. 11, p. 4624-4628, 1997. 